\title{
Study on Palmaris Longus Muscle Tendon Agenesis Among First Year Filipino Medical Students
}

\author{
Lamichhane $\mathrm{PS}^{1 *}$, Sharma K${ }^{1}$, Lamichhane $\mathrm{N}^{2}$ \\ 'Lecturer, Department of Radiology, ${ }^{2}$ Assocoiate Professor, Department of Neuropsychiatry \\ Gandaki Medical College \& Teaching Hospital, Pokhara, Nepal
}

\author{
Keywords \\ Agenesis, Gender, Laterality, \\ Palmaris longus.

\section{Corresponding author} \\ Dr. Pujan Sharma Lamichhane \\ Department of Radiology \\ Gandaki Medical College \& Teaching \\ Hospital, Pokhara, Nepal \\ Email: pujansharma1@hotmail.com
}

\begin{abstract}
Introduction: In the recent years palmaris longus muscle tendon (PLMT) has become an extensively and intensively studied muscle all over the world. The main reason for this is the importance of PLMT which was recognized with development of plastic and reconstructive surgery. The possibilities of PLMT use has become bigger and bigger each day
\end{abstract}

Objectives: The study aimed to evaluate the incidence of agenesis of palmaris longus muscle tendon among first year Filipino medical students at OLFU.

\begin{abstract}
Methods: This study was conducted at the Our Lady of Fatima University Medical Centre, Valenzuela City, Philippines. A semistructured proforma was used to record the relevant data for the study. The Thompson's test was used for assessing palmaris longus muscle tendon. After taking consent total of 503 first year Filipino medical students were involved.
\end{abstract}

Results: Out of total 503 subjects, 170 (33.80\%) were males and $333(66.20 \%)$ were females. Percentage of frequency of agenesis of palmaris longus muscle tendon in both genders was $17.05 \%$. There was no significant gender and laterality difference in the incidence of the agenesis of palmaris longus muscle tendon. That means there are equal chances of palmaris longus muscle tendon agenesis in both gender and the laterality.

Conclusions: There was no significant gender and laterality difference in the incidence of the agenesis of PLMT. This means that there are equal chances of PLMT agenesis in both gender and the laterality.

\section{INTRODUCTION}

People use their hands in both their daily activities and sports. Complex movements of hands are conducted due to the well-functioning coordination between a balanced muscular system and central nervous system.

In the recent years palmaris longus muscle tendon (PLMT) has become an extensively and intensively studied muscle all over the world. The main reason for this is the importance of PLMT which was recognized with development of plastic and reconstructive surgery.
The possibilities of PLMT use has become bigger and bigger each day ${ }^{13}$. It is easily accessible, and adequate in length and diameter. The absence of the muscle does not compromise flexion or any other motion at the wrist ${ }^{8}$.

PLMT is one of the superficial flexor muscles of the anterior anatomical compartment of the forearm and is one of the most variable muscles in the body. It is a slender, fusiform shaped muscle arising from the common flexor origin of the medial epicondyle of the humerus, passing between the flexor carpi radialis and flexor carpi ulnaris muscles, 
it ends as a slender, flattened tendon passing superficially over the transverse carpal ligament and inserting into the palmar aponeurosis ${ }^{17}$.

The action of the PLMT is to weakly flex the wrist and tense the palmar aponeurosis, synergized by flexor carpi radialis, flexor carpi ulnaris and flexor digitorum superficialis muscles. It is supplied by the median nerve ${ }^{5}$.

PLMT is extremely variable both in number and form. Its absence alone is variably reported in different populations depending on the race or ethnicity studied ${ }^{3}$.

The variability in the prevalence of PLMT agenesis among various ethnic groups has been established, and the surgeon's awareness of the prevalence in a population or ethnic group is desirable. This means that it is important to become aware of the prevalence of PLMT agenesis in the population being treated ${ }^{19,20,21}$.

There are various tests for examination of the presence or absence of the PLMT. For example; the Schaffer's test $(1909)^{18}$, the Mishra's test $(2001)^{12}$, the Pushpa kumar's "two-finger sign" method (2004) ${ }^{16}$ and the Thompson's test $(1921)^{22}$.

The incidence of PLMT agenesis has, to the best of our knowledge, not been reported in the Philippines. The purpose of this research is to evaluate the frequency of agenesis of PLMT among first year Filipino medical students at OLFU.

\section{Scope and Limitations of the Study}

Despite the obvious clinical importance of PLMT, there is a dearth of information in the literature on its occurrence in Filipino population. Hence, this study will be a landmark in assimilating the knowledge regarding the frequency of agenesis of the PLMT and its clinical relevance in general and its particular association in the Filipino population in terms of sex and the laterality. There may be several limitations in this study i.e. the study was conducted to determine the PLMT agenesis among first year medical students in Our Lady of Fatima University, Valenzuela City, Philippines, and generalizations cannot be made.

As the population size is small, the findings may not replicate in the general population of the Philippines.

\section{METHODS}

This is a qualitative and descriptive study done among first year Filipino medical students at Our Lady of Fatima University (SY, 2012 - 2013). In this study, 503 out of 648 students were included as 145 were not available during the period of data collection.

\section{Inclusion criteria}

1. First year Filipino medical students at OLFU (SY, 2012 2013), either sex, no history of known physical disabilities, any prior surgery (to the upper limbs) and any upper limb injuries leading to disruption of the anatomical structure.

A semi-structured proforma was formed to record the relevant data for the study. The Thompson's test was used for assessing PLMT ${ }^{22}$. The subjects were asked to make a fist and then flex the wrist and finally oppose the thumb and flex it over the fingers. Test was used too on both of the forearms of all individuals, where the PLMT was visually observed and palpated by an examiner. If PMLT is not visualized then it was taken as positive findings.

After explaining the nature of the study to the students in the classroom, an informed verbal consent was taken from those who fit in the inclusion criteria of the study. Thompson's test was demonstrated first to the participants, were asked to fill the proforma. After which, individual candidates were assessed on both the forearms using the test; then the findings were recorded in the sheet. The collected data were used for computation.

The descriptive analyses of the data were done by using SPSS-16 software and the difference among the sex and the sides of the limbs were analyzed by chi-square test.

\section{RESULTS}

In the total of 503 subjects, majority were females 333 (66.20\%) and 170 (33.80\%) were males. Palmaris longus muscle tendon (PLMT) agenesis was seen in 17.5\%. PLMT agenesis in the right, the left and both fore arms were seven (1.39\%), $15(2.98 \%)$ and two $(0.4 \%)$ respectively in the male subjects while the agenesis of PLMT in right, left and both forearms were 23 (4.57\%), 28 (5.57\%) and $13(2.58 \%)$ respectively in the female subjects. The data collected also presents total agenesis (right, left and bilateral forearms) of male subjects comprising 24 (4.77\%), and female subjects comprising 64 (12.70\%). The overall agenesis of PLMT in the right, left and both the forearms were 30 (5.96\%), 43 (8.55\%) and 15 (2.98\%) respectively in both the genders (See Table 1).

Table1: Distribution of PLMT agenesis

\begin{tabular}{lccc}
\hline Side of limbs & $\begin{array}{c}\text { Males } \\
(\mathbf{n = 1 7 0 )}\end{array}$ & $\begin{array}{c}\text { Females } \\
(\mathbf{n = 3 3 3 )}\end{array}$ & $\begin{array}{c}\text { Total } \\
(\mathbf{n = 5 0 3 )}\end{array}$ \\
\hline Right forearm & $7(1.39 \%)$ & $23(4.57 \%)$ & $30(5.96 \%)$ \\
Left forearm & $15(2.98 \%)$ & $28(5.57 \%)$ & $43(8.55 \%)$ \\
Bilateral forearms & $2(0.4 \%)$ & $13(2.58 \%)$ & $15(2.98 \%)$ \\
Total & $24(4.77 \%)$ & $64(12.72 \%)$ & $88(17.50 \%)$ \\
\hline
\end{tabular}


Using the two-tailed chi square test to determine the significant difference in the incidence of PLMT agenesis as to gender the computed $x^{2}$ value is 2.029 , whereas the tabular $x^{2}$ value is 3.841 at $95 \%$ significant level and the degree of freedom as 1 . The computed value is less than the tabular value and therefore, there is no significant difference of incidence of PLMT agenesis in both genders. Both genders have an equal chance of having a PLMT agenesis (See Table 2).

Table 2: Significant difference in PLMT agenesis as to gender (Chi- square test)

\begin{tabular}{lccc}
\hline \multirow{2}{*}{ Gender } & \multicolumn{2}{c}{$\begin{array}{c}\text { Agenesis of palmaris longus } \\
\text { muscle tendon }\end{array}$} & Total \\
\cline { 2 - 3 } & Positive & Negative & \\
\hline Males & 24 & 146 & 170 \\
Females & 64 & 269 & 333 \\
Total & 88 & 415 & 503 \\
\hline
\end{tabular}

Using the two-tailed chi square test to determine the significant difference in the incidence of PLMT agenesis as to laterality, the computed $x^{2}$ value is 1.828 whereas the tabular $\mathrm{x}^{2}$ value is 3.841 at $95 \%$ significant level with degree of freedom as 1 . The computed value is less than the tabular value, so the hypothesis is accepted. Therefore, there is no significant difference of incidence of PLMT agenesis in each side of forearm and there is no significant difference in the incidence of agenesis of PLMT as to laterality (See Table 3).

Table 3: Significant difference in PMLT agenesis as to laterality $\left(\mathrm{X}^{2}\right.$ test)

\begin{tabular}{cccc}
\hline $\begin{array}{c}\text { Sides of the } \\
\text { limbs }\end{array}$ & $\begin{array}{c}\text { Positive PLM } \\
\text { agenesis }\end{array}$ & $\begin{array}{c}\text { Negative PLM } \\
\text { agenesis }\end{array}$ & Total \\
\hline Right forearm & 45 & 458 & 503 \\
Left forearm & 58 & 445 & 503 \\
Total & 103 & 903 & 1006 \\
\hline
\end{tabular}

\section{DISCUSSION}

In the recent years, palmaris longus muscle tendon has become an extensively and intensively studied muscle all over the world. The main reason for this is the importance of palmaris longus muscle tendon, which was recognized with the development of plastic and reconstructive surgery $^{13}$. Many surgeons agree that the palmaris longus muscle tendon is the first choice as a donor tendon because it fulfills the necessary requirements of length, diameter and availability and can be used without producing any functional deformity to the hand ${ }^{23}$.
This study was an attempt to determine the incidence of the agenesis of PLMT in the first year Filipino medical students. In the present study PLMT agenesis was recorded in $17.50 \%$ of the population. The incidence rate of agenesis observed in our study is comparable to what was observed in an Indian study and a Nigerian study with recorded rates of $17.2 \%$ and $12.6 \%$ respectively ${ }^{5,10}$.

The highest prevalence rate in literature was observed to be $63.9 \%$ in a Turkish study ${ }^{4}$. Studies of Ahn in 2000 in Korea (0.9\%), Gangata in 2009 in Zimbabwe (1.5\%) and Igbigbiet et al in 1998 in Uganda (1.02\%) have reported lower incidence rates of agenesis compared to the present study ${ }^{1,7,9}$.

In our study, unilateral agenesis of PLMT (73 students) was common than bilateral agenesis (15 students). These findings are in agreement with the work done by many other researchers ${ }^{6,10,11}$. However, there were no differences in the agenesis of the PLMT on either gender. The incidence of agenesis of palmaris longus is $17.50 \%$ (14.11\% in males and $19.22 \%$ in females). This finding is supported by other published work ${ }^{2}$.

Unfortunately, we did not find any previous study using the Filipino population to compare. All the comparative discussions above were based on the findings of other countries.

\section{CONCLUSIONS}

Based on the chi-square computation and the comparison of the critical value, there was no significant gender and laterality differences in the incidence of the agenesis of PLMT. This means that there are equal chances of PLMT agenesis in both gender and the laterality.

\section{Recommendations}

1. Surgeons must be aware of the agenesis of PLMT in the population being treated because this tendon provides a very useful graft in plastic and reconstructive surgeries as well as hand surgery. In case of agenesis of this muscle, the surgeons may prepare to look for the alternatives in their plan.

2. Researchers in this field will benefit from the findings of this study as there has not been any such study in the Filipino population. Further studies in larger samples will be more comprehensive. We presume cadaveric study may give additional information regarding other anatomical variations like; reversed, duplicated, bifid, or hypertrophied palmaris longus muscles. 


\section{Limitations of the Study}

Since the study was conducted to determine the PLMT agenesis among first year medical students in Our Lady of Fatima University, Valenzuela City, Philippines, the findings cannot be generalized for population at large.

\section{REFERENCES}

1. Ahn DS, Yoon ES, Koo SH, Park SH. A prospective study of the anatomic variations of the median nerve in the carpal tunnel in Asians. Ann Plast Surg. 2000; 44(3): 282-7.

2. Ali MS, Mirna P, Cameron SF. A comparative study of plantaris and palmaris longus in South Indian population and their clinical applications. Plastic Surgery International Journal. 2012; 10(4): 1155.

3. Baral P, Bhattarai C, Poudel PP, Roy S, Banstola D, Shrestha RN. Anatomic variations of palmaris longus muscles in Nepalese. J-GMC-N. 2009; 12(3): $39-42$.

4. Ceyhan 0, Mavt A. Distribution of agenesis of Palmaris longus muscle in 12 to 18 years old age groups. Indian J Med Sci. 1997; 51(5): 156-60.

5. Enye LA, Saalu LC, Osinubi A. The prevalence of agenesis of palmaris longus muscle amongst students in two Lagos-based Medical Schools. Int J Morphol. (2010); 28(3): 849-854.

6. Eric M, Krivokuca D, Savovic S, Leksan I, Vucinic N. Prevalence of the palmaris longus through clinic evaluation. Surg Radio Anat. (2010); 32(4): 357-61.

7. Gangata H. The Clinical surface anatomy anomalies of the palmaris longus muscle in the Black African population of Zimbabwe and a proposed new testing technique. Clinical Anatomy. 2009; 22(2): $230-5$.

8. Henry Gray (1821-1865). Introduction page. "Anatomy of the Human Body". 20th edition. 1918.

9. Igbigbi PS, Ssekitoleko HA. Incidence of agenesis of the palmaris longus muscle in Ugandans. West African Journal of Anatomy. 1998; 6: 21-23.

10. Kapoor SK, Tiwari A, Kumar A, Bhatia R, Tantuway $\mathrm{V}$, Kapoor S. Clinical relevance of palmaris longus agenesis: Common anatomical aberration. Anatomical Science International. 2008; 83: 45-48.

11. Kose 0, Adanir O, Cirpar M, Kurklu M, Komurcu M. The prevalence of absence of the palmaris longus: A study in Turkish population. Arch Orthop Trauma
Surg. 2009; 129(5): 609-11.

12. Mishra S. Alternative tests in demonstrating the presence of palmaris longus. Indian J Plast Surg. 2001; 34: 12.

13. Norbert B, Ferenc R. General analysis of studies of palmaris longus muscle agenesis in different populations in recent past. Transcarpathian Hungarian Institute. 2011. Website URL:http:// www.gisap.eu/node/1596.

14. Powell BW, McLean NR, Jeffs JV. The incidence of a Palmaris longus tendon in patients with Dupuytren's disease. J Hand Surg B. 1986; 11(3): 382-384.

15. Pratt NE. Surface anatomy of upper extremity. In: Rehabilitation of the Hand-Surgery and Therapy. 1995; Vol I: 4th edn (Hunter JM, Mackin EJ, Callahan AD eds). Mosby, St Louis. 41-50.

16. Pushpakumar SB, Hanson RP, Carroll S. The 'two finger' sign: Absence of palmaris longus tendon in Indian population clinical examination of palmaris longus (PL) tendon. Br J Plast Surg. 2004; 57(1): 184-5. [PubMed]

17. Roohi SA, Choon-Sian L, Shalimar A, Tan GH, Naicker, AS. A study on the absence of palmaris longus in a multi-racial population. Malaysian Orthopaedic Journal. 2007; 1(1): 26-8.

18. Schaeffer JP. On the variations of the palmaris longus muscle. Anat Rec. 1909; 3(1): 275-8.

19. Sebastin SJ, Lim AYT, Wong HB. Clinical assessment of absence of the palmaris longus and its association with other anatomical anomalies - A Chinese population study. Ann Acad Med Singapore. 2006; 35(1): 249-253.

20. Sebastin SJ, Lim AY, Bee WH, Wong TC, Methil BV. Does the absence of the Palmaris longus affect grip and pinch strength? J Hand Surg Br. 2005; 30(4): 406-408.

21. Sebastin SJ. Puhaindran ME. Lim AY. Lim IJ, Bee WH. The prevalence of absence of the palmaris longus: A study in a Chinese population and are view of the literature. J Hand Surg. (Br). 2005; 30(1): 525-7.

22. Thompson NW, Mockford BF, Cran GW. Absence of the palmaris longus muscle: A population study. Ulster Med J. 2001; 70(1): 22-4.

23. Troha F, Baibak GJ, Kelleher JC. Frequency of the Palmaris longus tendon in North American Caucasians. Ann Plast Surg. 1990; 25(6): 477-478. 